\title{
Homogeneity of Cardiac Contraction Despite Physiological Asynchrony of Depolarization: A Model Study
}

\section{Citation for published version (APA):}

Kerckhoffs, R. C. P., Bovendeerd, P. H. M., Kotte, J. C. S., Prinzen, F. W., Smits, K., \& Arts, M. G. J. (2003). Homogeneity of Cardiac Contraction Despite Physiological Asynchrony of Depolarization: A Model Study. Annals of Biomedical Engineering, 31(5), 536-547. https://doi.org/10.1114/1.1566447

DOI:

10.1114/1.1566447

Document status and date:

Published: 01/01/2003

\section{Document Version:}

Publisher's PDF, also known as Version of Record (includes final page, issue and volume numbers)

\section{Please check the document version of this publication:}

- A submitted manuscript is the version of the article upon submission and before peer-review. There can be important differences between the submitted version and the official published version of record. People interested in the research are advised to contact the author for the final version of the publication, or visit the $\mathrm{DOI}$ to the publisher's website.

- The final author version and the galley proof are versions of the publication after peer review.

- The final published version features the final layout of the paper including the volume, issue and page numbers.

Link to publication

\section{General rights}

Copyright and moral rights for the publications made accessible in the public portal are retained by the authors and/or other copyright owners and it is a condition of accessing publications that users recognise and abide by the legal requirements associated with these rights.

- Users may download and print one copy of any publication from the public portal for the purpose of private study or research.

- You may not further distribute the material or use it for any profit-making activity or commercial gain

- You may freely distribute the URL identifying the publication in the public portal.

If the publication is distributed under the terms of Article 25fa of the Dutch Copyright Act, indicated by the "Taverne" license above, please follow below link for the End User Agreement:

www.tue.nl/taverne

Take down policy

If you believe that this document breaches copyright please contact us at:

openaccess@tue.nl

providing details and we will investigate your claim. 


\title{
Homogeneity of Cardiac Contraction Despite Physiological Asynchrony of Depolarization: A Model Study
}

\author{
R. C. P. Kerckhoffs, P. H. M. Bovendeerd, J. C. S. Kotte, F. W. Prinzen, K. Smits, and T. Arts \\ Department of Biomedical Engineering, Eindhoven University of Technology, Whoog 4.105, P.O. Box 513, 5600 Eindhoven, \\ The Netherlands
}

(Received 25 July 2002; accepted 24 January 2003)

\begin{abstract}
The use of mathematical models combining wave propagation and wall mechanics may provide new insights in the interpretation of cardiac deformation toward various forms of cardiac pathology. In the present study we investigated whether combining accepted mechanisms on propagation of the depolarization wave, time variant mechanical properties of cardiac tissue after depolarization, and hemodynamic load of the left ventricle (LV) by the aortic impedance in a threedimensional finite element model results in a physiological pattern of cardiac contraction. We assumed that the delay between depolarization for all myocytes and the onset of crossbridge formation was constant. Two simulations were performed, one in which contraction was initiated according to the regular depolarization pattern (NORM simulation), and another in which contraction was initiated after synchronous depolarization (SYNC simulation). In the NORM simulation propagation of depolarization was physiological, but wall strain was unphysiologically inhomogeneous. When simulating LV mechanics with unphysiological synchronous depolarization (SYNC) myofiber strain was more homogeneous and more physiologic. Apparently, the assumption of a constant delay between depolarization and onset of crossbridge formation results in an unrealistic contraction pattern. The present finding may indicate that electromechanical delay times are heterogeneously distributed, such that a contraction in a normal heart is more synchronous than depolarization. (C) 2003 Biomedical Engineering Society. [DOI: 10.1114/1.1566447]
\end{abstract}

Keywords-Electromechanics, Eikonal-diffusion equation, Hill.

\section{INTRODUCTION}

The normal heart beat is initiated by spontaneous electrical depolarization of the sinus node in the right atrium. The resulting depolarization wave propagates across both atria, passes the atrioventricular node and ventricular conduction system, and finally depolarizes both ventricles. Depolarization is followed by contraction of the myofibers. The normal contraction pattern of the

Address correspondence to P. H. M. Bovendeerd, Eindhoven University of Technology, Dept. Biomedical Engineering, P.O. Box 513, $5600 \mathrm{MB}$ Eindhoven, The Netherlands. Electronic mail: p.h.m.bovendeerd@tue.nl left ventricle (LV) may be affected by underperfusion $^{2,15,25,52}$ and abnormal conduction of the depolarization wave. ${ }^{34,53}$

With the rapid evolution of methods to determine myocardial deformation non-invasively, deduction of pathology from such measurements is a challenge. Size and location of ischemic regions were assessed by analysis of cardiac images with the help of mathematical models of cardiac mechanics. ${ }^{1,46} \mathrm{~A}$ next interesting challenge is to predict the pattern of contraction from a known pattern of electrical depolarization, or, vice versa, to deduce the sequence of electrical depolarization from non-invasively measured mechanical deformation. ${ }^{56}$ Understanding of electromechanical interaction becomes especially relevant because of the rapidly increasing interest in cardiac resynchronization.

We postulate that mathematical models, which combine wave propagation and wall mechanics, may provide new insights in interpreting cardiac deformation towards cardiac pathology. There are several models on myocardial electrophysiology (for an overview, see Ref. 27) and mechanics ${ }^{6,29,44,48}$ separately, but the behavior of the combination of the two principles in an entire ventricle is not well known.

It is known that timing of mechanical contraction determines the distribution of strain. ${ }^{4}$ It is also known that this timing is mainly determined by the pattern of depolarization. However, it has not been thoroughly investigated yet whether the combination of both apparently known principles into a comprehensive electromechanical model will result in a realistic pattern of contraction. In the present study, therefore, such combination of models has been designed. Simulations were assessed, focusing on the pattern of deformation. From possible discrepancies with experimental results, characteristics of electromechanical coupling were further unraveled.

In designing the model of left ventricular electromechanics, depolarization wave propagation was modeled using the eikonal diffusion equation. ${ }^{11}$ This equation solves the arrival time of the depolarization wave as a 
function of space, allowing for effects of anisotropic wave propagation and wave front curvature. The method was preferred over the well-known bidomain model because of computational efficiency. The solutions of the eikonal diffusion equation and the bidomain model were reported to match closely. ${ }^{9}$

Left ventricular electromechanics were modeled in a three-dimensional (3D) finite element mesh. Wall mechanics were solved by equations of force equilibrium. Myocardial material was considered anisotropic, nonlinearly elastic and time dependent. ${ }^{5,19,44}$ The aortic input impedance was simulated by a three-element windkessel model. ${ }^{55}$ First, a cardiac contraction cycle was simulated for a regular pattern of depolarization. In particular, we assumed that the delay between depolarization and the onset of crossbridge formation was the same for all myofibers. Simulated results on midwall myofiber strain, epicardial myofiber strain, and the distribution of external work were compared with reported experimental findings. ${ }^{12,18,34,35,56}$ The sensitivity of wall mechanics to timing of depolarization was investigated with the help of a simulation where effects of time differences were excluded by synchronous depolarization of all myofibers.

\section{MATERIALS AND METHODS}

The mathematical model of LV electromechanics has been designed in three modules, describing (1) LV geometry and myofiber orientation, (2) depolarization wave propagation, and (3) LV wall mechanics.

\section{Geometry and Myofiber Orientation}

In the reference state, defined by zero transmural pressure, the LV wall was represented by a thickwalled truncated ellipsoid. ${ }^{6}$ Volumes of LV wall, cavity, and papillary muscles were 140,40 , and $4 \mathrm{ml}$, respectively. Local myofiber orientation was quantified by helix angle $\alpha_{h}$, and the transverse angle $\alpha_{t}$. The helix angle spans the local circumferential direction and the projection of the myofiber orientation on the plane parallel to the wall. The transverse angle spans the local circumferential direction and the projection of the myofiber orientation on the plane perpendicular to the local longitudinal direction. Myofiber orientations were obtained by optimizing for homogeneous myofiber shortening during ejection. ${ }^{38}$ Thus, the transmural courses of $\alpha_{h}$ and $\alpha_{t}$ varied throughout the wall according to Fig. 1.

\section{Depolarization Wave}

For the moment of depolarization $t_{\text {dep }}$ within the wall the eikonal-diffusion equation (rewritten from Ref. 11) was solved for the gradient of $t_{\text {dep }}\left(\nabla t_{\text {dep }}\right)$ :

$$
c_{f} \sqrt{\boldsymbol{\nabla} t_{\mathrm{dep}} \cdot \mathbf{M} \cdot \boldsymbol{\nabla} t_{\mathrm{dep}}}-k_{0} \boldsymbol{\nabla} \cdot\left(\mathbf{M} \cdot \boldsymbol{\nabla} t_{\mathrm{dep}}\right)=1 .
$$

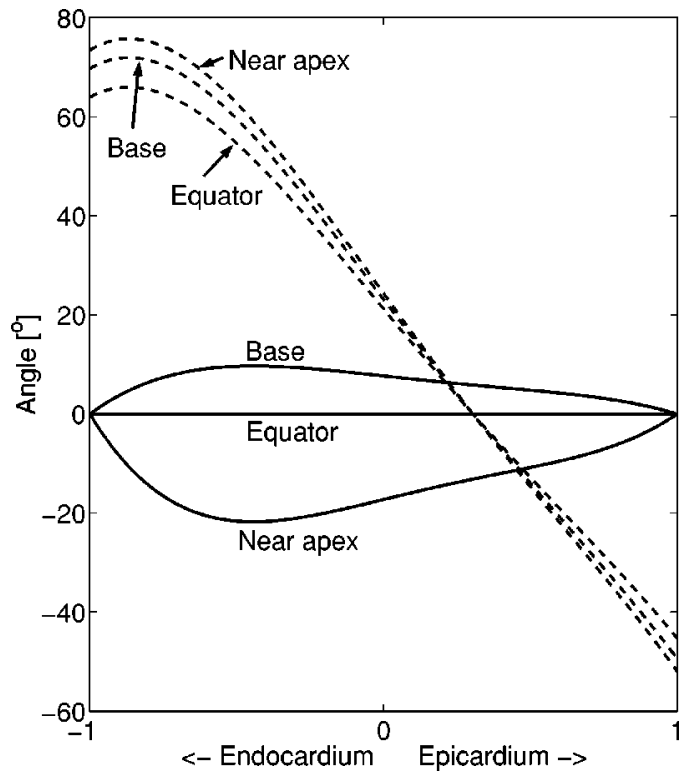

FIGURE 1. Myofiber orientation as a function of transmural position at several longitudinal positions; the helix (- -) angle and transverse angle (-) are components of myofiber orientation, as defined in the text.

Parameter $c_{f}(0.67 \mathrm{~m} / \mathrm{s})$ represents the velocity of the depolarization wave along the myofiber direction. Constant $k_{0}\left(2.1 \times 10^{-4} \mathrm{~m}^{2} \mathrm{~s}^{-1}\right)$ determines the influence of wave-front curvature on wave velocity. Dimensionless tensor $\mathbf{M}$ describes anisotropy of wave propagation in the global coordinate system. Tensor $\mathbf{M}^{*}$ is referred to a local coordinate system, aligned with the myofiber, and is related to $\mathbf{M}$ by

$$
\mathbf{M}=\mathbf{R} \mathbf{M}^{*} \mathbf{R}^{T} .
$$

Rotation tensor $\mathbf{R}$ is associated with the myofiber orientation; index $T$ indicates the transpose. The largest principal component along the myofiber direction is $m_{11}^{*}$ $=1$. The other principal components are $m_{22}^{*}=m_{33}^{*}$ $=0.38$, indicating that the wave-front velocity perpendicular to the myofiber direction $\left(c_{t}=c_{f} \sqrt{m_{22}^{*}}\right.$ $=0.42 \mathrm{~m} / \mathrm{s}$ ) is slower. Parameters $c_{f}, c_{t}$, and $k_{0}$ were derived from Ref. 45.

To simulate the effect of the fast conducting Purkinje fibers, parameter $c_{f}$ had a six-fold value in the subendocardial layer between apex and equator (Fig. 2). With the assumption that the LV is electrically insulated, the wave fronts are perpendicular to the boundary $\Gamma_{\text {ext }}$, being the basal, endocardial, and epicardial surface of the cardiac wall:

$$
\mathbf{n} \cdot \mathbf{M} \nabla t_{\text {dep }}=0 \text { for } \quad \Gamma_{\text {ext }} .
$$




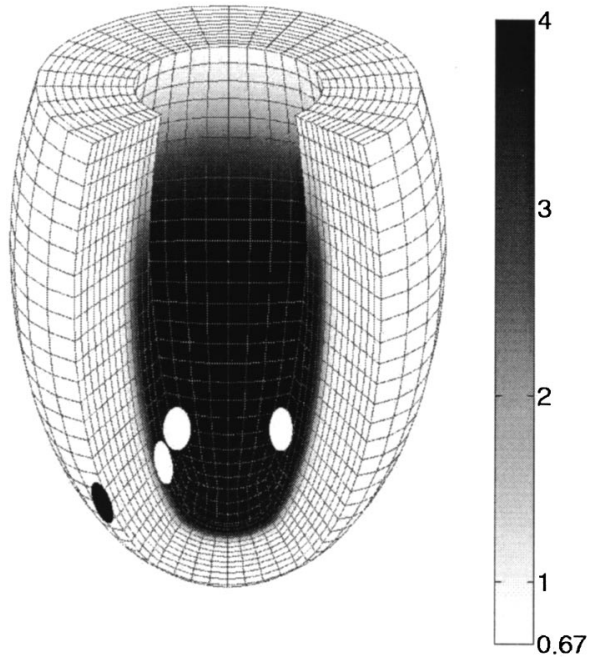

FIGURE 2. Distribution of depolarization wave velocity $c_{f}(\mathrm{~m} / \mathrm{s})$ parallel to the myofiber direction. In most of the myocardium $c_{f}=0.67 \mathrm{~m} / \mathrm{s}$. At the subendocardium between apex and equator $c_{f}=4 \mathrm{~m} / \mathrm{s}$ with a narrow, smooth transition zone around. The small circular regions represent the regions of initiation of ventricular depolarization, as indicated by $\Gamma_{\text {stim }}$ in Eq. (4).

Vector $\mathbf{n}$ represents the orthogonal on the boundary $\Gamma_{\text {ext }}$. Normally, depolarization was assumed to start $t_{\text {dep }}$ simultaneously at four locations $\Gamma_{\text {stim }}$ (Fig. 2) in the LV. Three locations are situated at the $\mathrm{LV}$ subendocardium ${ }^{13}$ and one location at the right ventricle (RV) subendocardium: ${ }^{14}$

$$
t_{\text {dep }}=0 \text { for } \Gamma_{\text {stim }} \text {. }
$$

\section{Modeling Mechanical Properties of Cardiac Tissue}

The mechanical behavior of the cardiac tissue depended on time as expressed by the constitutive equations. Total Cauchy stress $\boldsymbol{\sigma}$ was composed of a passive $\left(\boldsymbol{\sigma}_{p}\right)$ and an active component $\left(\sigma_{a}\right)$ along the myofiber direction $\mathbf{e}_{f}$ :

$$
\boldsymbol{\sigma}=\boldsymbol{\sigma}_{p}+\sigma_{a} \mathbf{e}_{f} \mathbf{e}_{f} .
$$

Passive tissue stress $\boldsymbol{\sigma}_{p}$ was related to the deformation gradient tensor $\mathbf{F}$ and the Green Lagrange strain tensor $\mathbf{E}$ by

$$
\boldsymbol{\sigma}_{\mathbf{p}}=\frac{1}{\operatorname{det}(\mathbf{F})} \mathbf{F} \cdot \frac{\partial W_{p}}{\partial \mathbf{E}} \cdot \mathbf{F}^{T} \quad \text { with } \quad \mathbf{E}=\frac{1}{2}\left(\mathbf{F}^{T} \cdot \mathbf{F}-\mathbf{I}\right) .
$$

Symbol I represents the identity tensor. $W_{p}$ represents the deformation energy density as a function of strain $\mathbf{E}$, being composed of an isotropic component $W_{i}$, related
TABLE 1. Passive material tissue properties, based on uniand biaxial measurements of myocardial tissue slabs (see Ref. 31) and on the pressure-volume relationship of passive inflation of the LV (see Ref. 30).

\begin{tabular}{lccccc}
\hline$a_{0}$ & $a_{1}$ & $a_{2}$ & $a_{3}$ & $a_{4}$ & $a_{5}$ \\
\hline $\mathrm{kPa}$ & $\ldots$ & $\ldots$ & $\mathrm{kPa}$ & $\ldots$ & $\mathrm{kPa}$ \\
0.5 & 3.0 & 6.0 & 0.01 & 60 & 55 \\
\hline
\end{tabular}

to tissue shape change, a component $W_{f}$, related to the extra stiffness of the material in the myofiber direction, and a component $W_{v}$, related to volume change:

$$
W_{p}=W_{i}+W_{f}+W_{v},
$$

with

$$
\begin{gathered}
W_{i}=a_{0}\left(e^{a_{1} I_{1}^{2}+a_{2} I_{2}}-1\right), \\
W_{f}=a_{3}\left(e^{a_{4} E_{f}^{2}}-1\right), \\
W_{v}=a_{5}\left[\operatorname{det}\left(\mathbf{F}^{T} \cdot \mathbf{F}\right)-1\right]^{2} .
\end{gathered}
$$

$I_{1}$ and $I_{2}$ represent the first and second invariants of $\mathbf{E}$ respectively. ${ }^{24}$ Material parameter values $a_{0}$ through $a_{5}$ are listed in Table 1.

$E_{f}$ represents the Green Lagrange strain component along the myofiber direction:

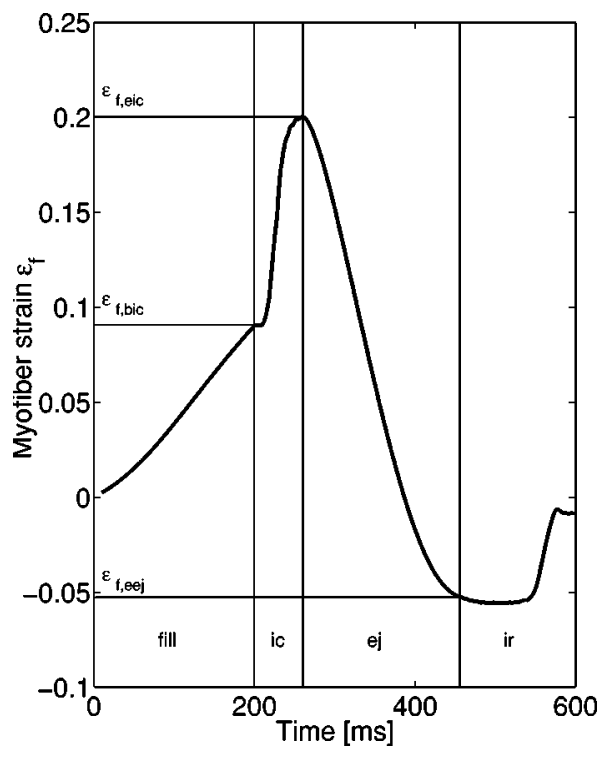

FIGURE 3. Myofiber strain $\epsilon$ during the cardiac cycle. fill filling; ic isovolumic contraction; ej ejection; ir isovolumic relaxation; $\epsilon_{f, \text { bic }}$ myofiber strain at beginning of isovolumic contraction; $\epsilon_{f \text {,eic }}$ myofiber strain at end of isovolumic contraction; and $\epsilon_{f, \text { eej }}$ myofiber strain at end of ejection. 


$$
E_{f}=\frac{1}{2}\left[\left(\frac{l_{s}}{l_{s 0}}\right)^{2}-1\right],
$$

with actual sarcomere length $l_{s}$, and sarcomere length in the reference state $l_{s 0}=1.9 \mu \mathrm{m}$.

This strain energy formulation is a slight modification of the one proposed earlier, ${ }^{37}$ i.e., the term $a_{4} E_{f}^{2}$ was removed from the exponent in $W_{i}$, and put in a separate term $W_{f}$ for a better description of the increasing passive stiffness for large sarcomere lengths. ${ }^{19}$

The characteristics of active stress $\sigma_{a}$ were modeled using a contractile element, with length $l_{c}$, in series with an elastic element, with length $l_{s}-l_{c}{ }^{5}$ The magnitude of $\sigma_{a}$ was described by

$$
\sigma_{a}=f_{1}\left(t_{a}, l_{s}, l_{c}\right),
$$

where $t_{a}$ represents time elapsed since depolarization. The time course of the $l_{c}$ is described by a first order differential equation:

$$
\frac{\partial l_{c}}{\partial t}=f_{2}\left(l_{s}-l_{c}\right)
$$

The used functions $f_{1}$ and $f_{2}$ have been described in the Appendix.

\section{Modeling Left Ventricular Mechanics}

Within the cardiac wall the equation of conservation of momentum was used while neglecting volumetric and inertial forces:

$$
\boldsymbol{\nabla} \cdot \boldsymbol{\sigma}=\mathbf{0}
$$

Pressure loads on the endocardium and epicardium were homogeneous, and equal to LV cavity pressure $p_{l v}$ and zero, respectively:

$$
\begin{gathered}
\mathbf{n} \cdot \boldsymbol{\sigma} \cdot \mathbf{n}=0 \quad \text { at the epicardium, } \\
\mathbf{n} \cdot \boldsymbol{\sigma} \cdot \mathbf{n}=p_{l v} \quad \text { at the endocardium. }
\end{gathered}
$$

To prevent rigid body motion, motion in the base to apex direction was set to zero at the base. In three points (anterior, posterior, and lateral) at the basal endocardium circumferential motion was also set to zero.

LV mitral inflow was simulated by quasi-static increase of pressure in the nonactivated LV from 0 to 1 $\mathrm{kPa}$ in pressure steps of $0.05 \mathrm{kPa}$. LV pressure in the isovolumic contraction and relaxation phases was estimated $^{6}$ such that LV cavity volume remained constant within $\pm 0.5 \%$. Aortic flow and pressure were related by a realistic three-element Windkessel model, ${ }^{55}$ being composed of a flow resistance $\left(1.5 \times 10^{7} \mathrm{~Pa} \mathrm{~s} \mathrm{~m}^{-3}\right)$ in series with a compliance $\left(1.0 \times 10^{-9} \mathrm{~m}^{3} \mathrm{~Pa}^{-1}\right)$ that was parallel to the peripheral flow resistance (1.4 $\times 10^{8} \mathrm{~Pa} \mathrm{~s} \mathrm{~m}^{-3}$ ). The aortic valve opened when LV pressure exceeded aortic pressure, being set at $10 \mathrm{kPa}$. Reversal of aortic flow closed the valve.

\section{Numerical Implementation}

The eikonal-diffusion equation with boundary conditions [Eqs. (1)-(4)] was solved using a Galerkin type finite element method with eight-noded hexahedral elements with trilinear interpolation. The LV wall was subdivided into 9984 elements, with 11037 degrees of freedom. This resulted in a mean spatial resolution of about $2 \mathrm{~mm}$. The solution was facilitated by gradual increase of the nonlinear term in each succesive iteration. ${ }^{3,45} \mathrm{~A}$ classical upwind scheme (Streamline Upwind Petrov Galerkin $^{8}$ ) was used to stabilize the finite element calculations. $^{10}$

The equations related to mechanics [Eqs. (14)-(16)] were solved using a Galerkin type finite element method with 27-noded hexahedral elements with triquadratic interpolation. The LV wall was subdivided into 108 elements, with 3213 degrees of freedom. A NewtonRaphson iterative procedure was used, and a NewtonCotes integration scheme ${ }^{21}$ was used with the integration points at the node positions.

All equations were solved on a 64 bit Origin 200 computer (SGI, Mountain View, CA), using a single processor at $225 \mathrm{MHz}$. The finite element calculations were performed with the FORTRAN77 compiler based package SEPRAN (SEPRA, Leidschendam, the Netherlands) on a UNIX platform.

\section{Simulations}

Two simulations were performed, one in which contraction was initiated according to the regular electrical depolarization pattern (NORM simulation) with a constant electromechanical delay of $0 \mathrm{~ms}$ for all myofibers and another in which contraction was unphysiologically synchronously initiated (SYNC simulation). Global hemodynamics, three-dimensional distributions of electrical depolarization time, myofiber stress and strain as a function of time, and stroke work density were calculated. Sarcomere length $l_{s}$ at the anterior and posterior midwall and epicardium, was calculated as a function of left ventricular volume $V_{\text {lv }}$, normalized to wall volume $V_{w}$. The ratio $\Delta l_{s}\left(\Delta V_{\mathrm{lv}} V_{w}^{-1}\right)^{-1}$ during ejection was estimated by linear regression.

Natural myofiber strain $\epsilon_{f}$ was defined as 


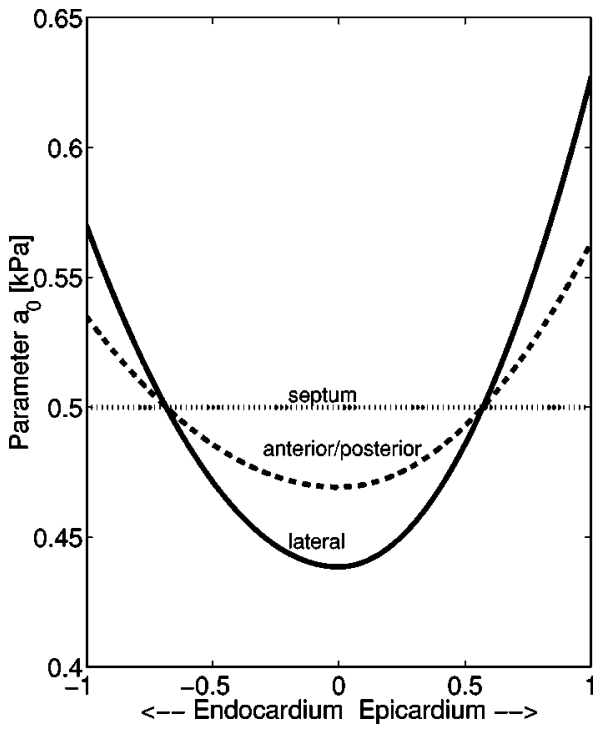

FIGURE 4. Distribution of parameter $a_{0}(\mathrm{kPa}$, Table 1$)$ in the HETER simulation with heterogeneous passive material properties.

$$
\epsilon_{f}=\ln \left(\frac{l_{s}}{l_{s 0}}\right) .
$$

Myofiber strain during isovolumic contraction and ejection $\epsilon_{f, i c}$ and $\epsilon_{f, e j}$, respectively, were defined as

$$
\begin{aligned}
& \epsilon_{f, \mathrm{ic}}=\epsilon_{f, \mathrm{eic}}-\epsilon_{f, \mathrm{bic}}, \\
& \epsilon_{f, \mathrm{ej}}=\epsilon_{f, \mathrm{eej}}-\epsilon_{f, \text { eic }},
\end{aligned}
$$

where $\epsilon_{f \text {,bic }}, \epsilon_{f \text {,eic }}$, and $\epsilon_{f \text {,eej }}$ are shown in Fig. 3.

Stroke work density $W_{f}\left(\mathrm{~J} \mathrm{~m}^{-3}\right)$ was defined as

$$
W_{f}=\oint_{\text {cardiaccycle }} \sigma_{f} d \epsilon_{f},
$$

where $\sigma_{f}$ is the total Cauchy myofiber stress in the tissue.

The effect of restricting wall motion at the base has been investigated by performing a simulation BOUN with an additional restriction of radial motion at the endocardial basal contour. The effect of heterogeneity in the distribution of passive stiffness has been investigated in simulation HETER, having a gradient in parameter $a_{0}$ (Table 1) according to Fig. 4, as based on measurements reported earlier. ${ }^{30,31}$ The effect of having a transmural gradient in end-diastolic sarcomere length has been investigated in simulation LS0, where initial sarcomere length $l_{s 0}$ [Eq. (11)] varied linearly from $1.84 \mu \mathrm{m}$ at the endocardium to $1.96 \mu \mathrm{m}$ at the epicardium. ${ }^{39}$

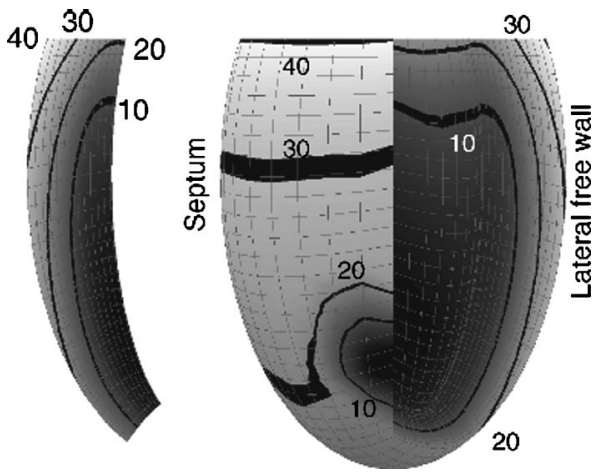

FIGURE 5. Map of depolarization times ( $\mathrm{ms}$ ) as simulated for a regular heart beat. Depolarization starts at $t_{\text {dep }}$. The left panel represents a cross-section of the septum. The right panel represents a view of the left ventricle with a $90^{\circ} \mathrm{sec}-$ tion removed, exposing a cross section of the $L V$ free wall and the lateral endocardium.

In the simulations BOUN, HETER, and LSO, myofiber contraction was initiated by the depolarization pattern, as calculated in the NORM simulation.

The differences of the test simulations with the NORM simulation were expressed in the square root of the mean of the squared differences, as normalized to the the volume-weighted mean value $(\mathrm{rms} \%)$.

To assess whether meshing was sufficiently fine, a simulation of depolarization wave propagation was performed with four times as many elements, resulting in a mean resolution of $1.4 \mathrm{~mm}$. In the transmural direction, where the largest gradients were found, resolution was $0.8 \mathrm{~mm}$. Similarly, for the mechanics, the number of elements was doubled.

\section{RESULTS}

\section{Depolarization Wave}

For solving the eikonal-diffusion equation calculation time was approximately $4 \mathrm{~h}$. In Fig. 5 the calculated regular depolarization pattern has been mapped. This map was used to initiate contraction in the NORM simulation, with constant electromechanical delay. The wave started in the four regions, shown in Fig. 2, and propagated to apex and base, and from endocardium to epicardium. After $20 \mathrm{~ms}$ the epicardium at the left ventricular free wall was reached. The epicardial free wall near the base was depolarized last at $43 \mathrm{~ms}$.

\section{Cardiac Mechanics}

Calculation time for solving the equations related to mechanics was approximately $10 \mathrm{~h}$. 

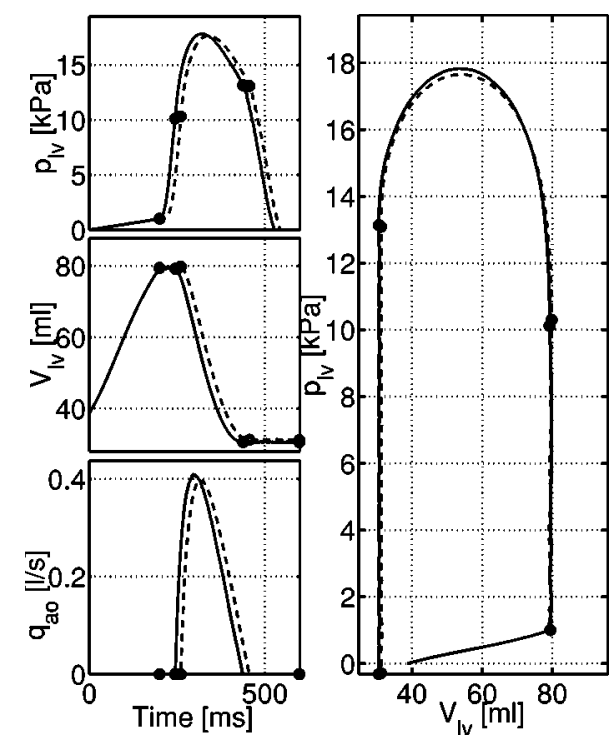

FIGURE 6. Global hemodynamics in simulation NORM (- -) and SYNC (-). The left panel represents from top to bottom the left ventricular pressure $p_{\mathrm{lv}}$, cavity volume $V_{\mathrm{Iv}}$, and aortic flow $q_{\mathrm{ao}}$ as a function of time. Dots indicate moments of opening and closure of the valves. The right panel represents the pressure-volume loops.

\section{Global Hemodynamics}

In both the NORM and SYNC simulations hemodynamics were similar (Fig. 6, Table 2). In the NORM simulation depolarization pressure developed about 22 ms later than in the SYNC simulation. This difference can be explained by the fact that in the SYNC simulation contraction started at $t_{\text {dep }}$, whereas in the NORM simulation starting time was distributed over the time interval between 0 and $43 \mathrm{~ms}$.

\section{Local Mechanics}

Myofiber Strains. In the NORM simulation early depolarized myofibers shortened during the isovolumic contraction phase, while late activated myofibers were prestretched (Fig. 7; Fig. 8, left panel). Both during isovolumic contraction and during ejection phase myofiber shortening was more homogeneously distributed in the SYNC simulation than in the NORM simulation (Table 3).

Myofiber Stresses. The distribution of myofiber stress is quite insensitive to the pattern of depolarization (Fig. 8). After a change in depolarization sequence, during the ejection phase relative changes in myofiber stress were considerably smaller than these changes in myofiber strain.

Stroke Work Density. The area of a workloop (Fig. 8,
TABLE 2. Hemodynamic variables in the NORM (with regular depolarization) and SYNC (with synchronous depolarization) simulations; $\Delta t_{\text {ic }}$ duration of isovolumic contraction phase; $\Delta t_{\mathrm{ej}}$ duration of ejection phase; $p_{l v, \text { max }}$ maximum LV pressure; $d p / d t_{\max }$ maximum first time derivative of LV pressure; $q_{a o, \max }$ maximum aorta flow; $V_{l v \text {, be }}$ and $V_{l v \text {,ee }} L V$ cavity volume at beginning and end of the ejection phase, respectively; $V_{w}$ LV wall volume; $V_{s}$ stroke volume; EF ejection fraction.

\begin{tabular}{lccc}
\hline & & NORM & SYNC \\
\hline$\Delta t_{\text {ic }}$ & $\mathrm{ms}$ & 60 & 44 \\
$\Delta t_{\mathrm{ej}}$ & $\mathrm{ms}$ & 196 & 194 \\
$p_{l v, \max }$ & $\mathrm{kPa}$ & 17.7 & 17.8 \\
$d p / d t_{\max }$ & $\mathrm{kPa} / \mathrm{s}$ & 370 & 332 \\
$q_{a o, \max }$ & $\mathrm{ml} / \mathrm{s}$ & 398 & 409 \\
$V_{l v, \mathrm{be}} / V_{w}$ & $\ldots$ & 0.60 & 0.60 \\
$V_{l v, \mathrm{ee}} / V_{w}$ & $\ldots$ & 0.23 & 0.23 \\
$V_{s}$ & $\mathrm{ml}$ & 48.6 & 48.7 \\
$\mathrm{EF}$ & $\%$ & 60.9 & 61.4 \\
\hline
\end{tabular}

right panel) represents work per unit of tissue volume, or stroke work density (Fig. 9). In the NORM simulation stroke work density in the early-depolarized regions was lowest and gradually increased towards the latedepolarized regions. Comparing the NORM with the SYNC simulation, mean stroke work density appeared similar (Fig. 8). In the NORM simulation however, stoke work density was much more inhomogeneous than in the SYNC simulation. The mean values of myofiber strain, stress, and work in Table 3 were calculated in the free wall, transmurally from $\frac{1}{4}$ to $\frac{3}{4}$ from base to apex.

In Table 4, for the NORM and SYNC simulation the change in sarcomere length per change in cavity volume has been shown for various locations in the left ventricle.
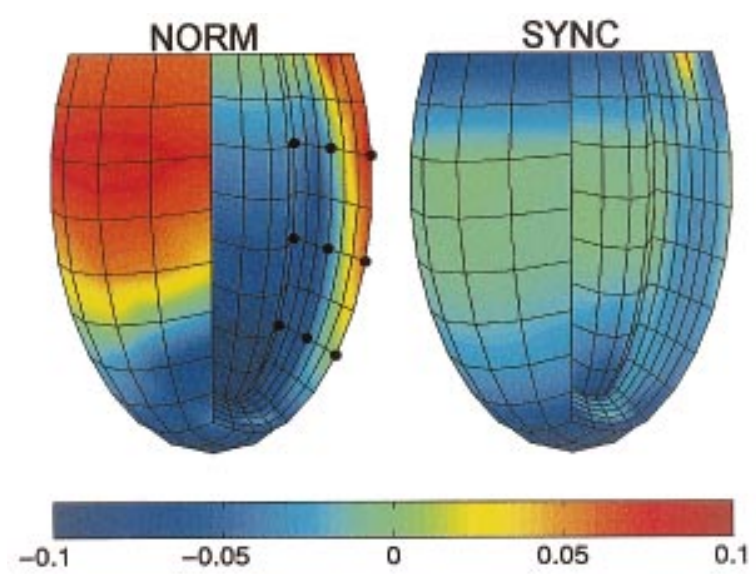

FIGURE 7. Distribution of myofiber strain during the isovolumic contraction phase (strain at the end minus strain at the beginning of the isovolumic contraction phase) for the NORM simulation (left) and the SYNC simulation (right) in an anterior view of the LV with septum on the left, and free wall on the right side. Notice that in this figure early shortening and prestretch occur as negative and positive strains, respectively. The circular dots indicate positions in the LV free wall, for which myofiber stress and strain are plotted in Fig. 8. 
a) Myofiber strain

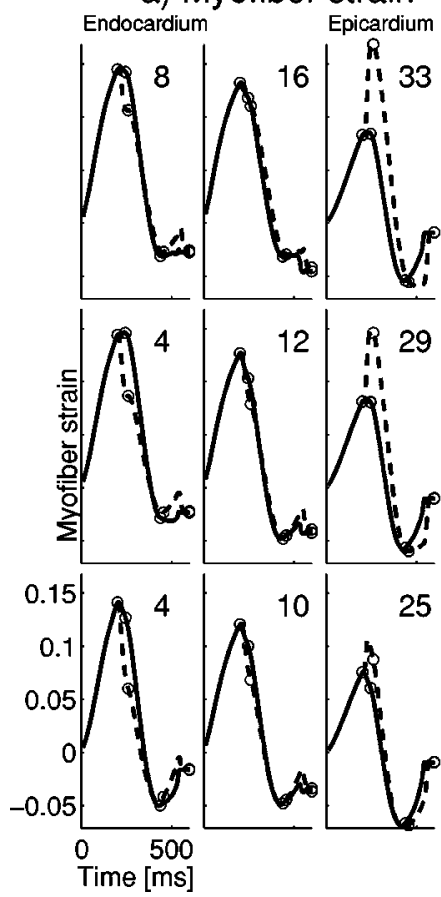

b) Myofiber stress [kPa]
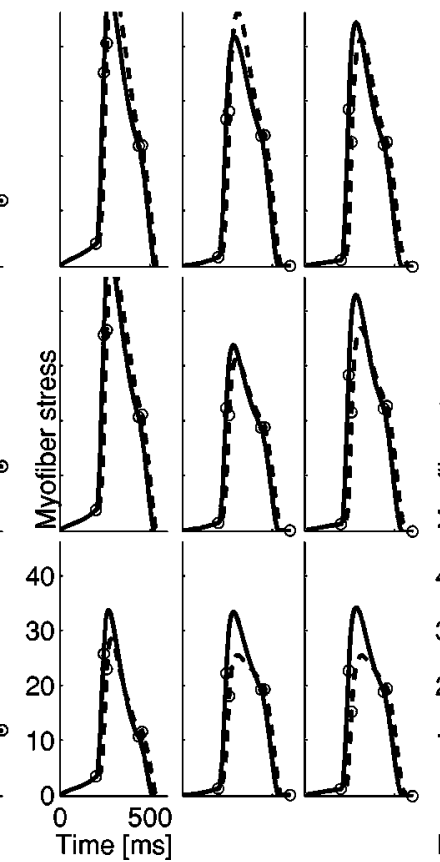

c) Workloops

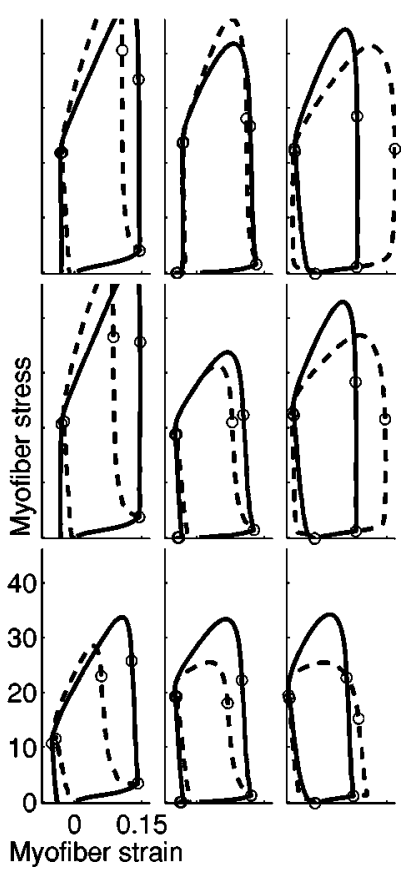

FIGURE 8. (a) Myofiber strain as a function of time for three positions transmurally and three positions from base (top) to apex (bottom). Plots were obtained for the NORM simulation (- $)$ and the SYNC simulation (-). The circles in the curves indicate moments of opening and closure of cardiac valves. The printed numbers are the electrical depolarization times (ms) for the NORM simulation; (b) myofiber stress as a function of time for the same positions and simulations as in (a); and (c) myofiber stress-strain loops for the same positions and simulations as in (a).

For comparison, similar data MEAS were obtained from measurements reported on canine hearts. ${ }^{18}$ For both SYNC and MEAS, myofiber shortening at the epicardium was slightly less than at midwall. Differences between anterior and posterior locations were not significant. For the NORM simulation, myofibers in the epicardium shorten more than at midwall. Effects of transmural redistribution of initial sarcomere length in the LS0 simulation, of different boundary conditions in the BOUN simulation, and of passive stiffness in the
HETER simulation were similar (Table 5). Myofiber shortening during isovolumic contraction was affected, but myofiber stress and strain during ejection did not change by more than $8.5 \%$.

For the depolarization wave, mesh refinement resulted in a root-mean-square value (rms) of the change in calculated depolarization time of $1.4 \mathrm{~ms}$. Mesh refinement in solving mechanics changed myofiber strain and stress by less than $0.4 \%$ and $0.1 \%$, respectively, during the ejection phase.

TABLE 3. Myofiber work, stress, and strain (mean $\pm s d$.) in the transmural equatorial region (Equator) and at the epicardium only (Epi) in the free wall for both the NORM and SYNC simulations and measurements (see Ref. 12): NORM simulation with regular depolarization pattern; SYNC simulation with synchronous depolarization; MEAS epicardial measurements; $W_{f}$ myofiber regional external work; $\sigma_{f, \text { ej }}$ myofiber stress during ejection; $\epsilon_{f, \text { ic }}$ myofiber strain during isovolumic contraction; and $\epsilon_{f, \text { ej }}$ myofiber strain during ejection.

\begin{tabular}{|c|c|c|c|c|c|}
\hline & & & NORM & SYNC & MEAS \\
\hline \multirow[t]{4}{*}{ Equator } & $W_{f}$ & $\mathrm{~kJ} \mathrm{~m}^{-3}$ & $4.45 \pm 1.59$ & $4.84 \pm 0.54$ & \\
\hline & $\sigma_{f, \mathrm{ej}}$ & $\mathrm{kPa}$ & $22.9 \pm 2.68$ & $23.8 \pm 2.34$ & \\
\hline & $\epsilon_{f, \text { ic }}$ & $\cdots$ & $-0.021 \pm 0.048$ & $-0.015 \pm 0.009$ & \\
\hline & $\epsilon_{f, \mathrm{ej}}$ & $\cdots$ & $-0.138 \pm 0.043$ & $-0.146 \pm 0.010$ & \\
\hline \multirow[t]{2}{*}{ Epi } & $\epsilon_{f, \text { ic }}$ & $\cdots$ & $0.052 \pm 0.026$ & $0.000 \pm 0.004$ & $-0.034 \pm 0.017$ \\
\hline & $\epsilon_{f, \mathrm{ej}}$ & $\cdots$ & $-0.190 \pm 0.027$ & $-0.135 \pm 0.004$ & $-0.098 \pm 0.012$ \\
\hline
\end{tabular}




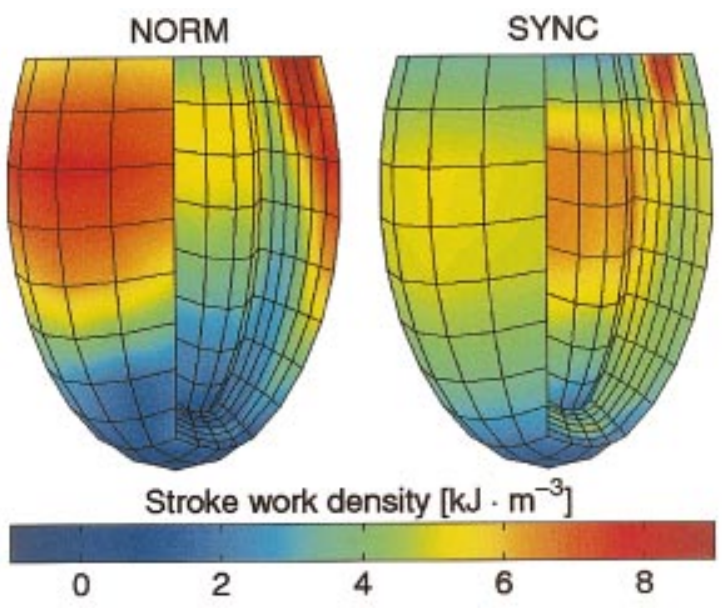

FIGURE 9. Stroke work density $\left(\mathrm{kJ} \mathrm{m}^{-3}\right)$ for the NORM and SYNC simulations in an anterior view of the LV with septum on the left, and free wall on the right side.

\section{DISCUSSION}

Simulations with our model predict that a physiological sequence of depolarization results in an unphysiologically non-uniform contraction pattern. Making the sequence of depolarization unphysiologically synchronous, the simulated contraction pattern appears physiologic. First we will discuss to what extent this discrepancy might be attributed to the simplifying assumptions in the mathematical model. Subsequently, it will be discussed if the findings can be explained by physiological processes, not yet implemented in the model.

\section{Model}

The LV geometry was simplified to a prolate ellipsoid. Near the base, the ellipsoid is truncated, thus requiring appropriate boundary conditions for motion of the wall. In the NORM and SYNC simulations rotational motion was prohibited at the endocardial basal contour, while radial motion of the base was allowed. Due to these boundary conditions, the wall tended to orient perpendicularly to the basal plane. This resulted in some prestretching at the base in the SYNC simulation (Fig. 7). To estimate the effect of constraining motion of the base, the results of the NORM simulation were compared to that of a simulation BOUN by which radial motion at the base was also prohibited. The distribution of stress and strain was severely affected near the base but much less in other regions of the LV. During ejection, below the equator a change of the boundary condition at the base affects both myofiber stress and myofiber strain by $\leqslant 8.1 \%$.

In simulations, LV wall mechanics appear sensitive to the choice of myofiber orientation. ${ }^{7}$ In view of a limited accuracy of available experimental data and the presence of biological variation, myofiber orientation is obtained by optimization on a homogeneous distribution of myofiber stress in the wall. ${ }^{38}$ The used distribution of myofiber orientation is within the range of reported anatomical measurements. ${ }^{16,43}$

The effect of fast propagation in the Purkinje system has been modeled in a continuum approach, characterized by a high depolarization wave velocity near the endocardium. More accurate descriptions cannot be made easily, because biological variance in the Purkinje system is considerable..$^{26,28,49}$ Our description has been based on an average of experimental data. ${ }^{14,13,41,42}$ Normally, for a detailed description of depolarization wave propagation, a resolution is needed of about $0.2 \mathrm{~mm}$, especially near strong wave front curvatures. For the conditions of our simulations, a $2 \mathrm{~mm}$ resolution appeared sufficient. Mesh refinement did not change the solution significantly.

Passive myocardial tissue is orthotropic due to the sheet structure of the myocardium. ${ }^{22}$ Sheets have less influence on deformation in systole than in diastole. ${ }^{48}$ Focusing on systole, the sheet structure has been neglected by considering passive myocardial tissue to be transversely isotropic. Active material was modeled uniaxially. An active component of transverse stiffness is shown to exist, ${ }^{23}$ but appears not to affect the pattern of early myofiber shortening and prestretching as shown in a model study. ${ }^{47}$ We assumed homogeneneity of material properties throughout the LV wall. However, some studies indicate heterogeneity of passive material properties. ${ }^{31}$ In the HETER simulation, myofiber strain and stress during the isovolumic and ejection phase seems practically not affected by the introduced heterogeneity of material properties (Table 5). Residual stress and strain $^{32}$ might affect systolic stresses through a trans-

TABLE 4. Sarcomere shortening $I_{s}$ per ejected volume $V_{L v}$, normalized to wall volume $V_{w}$, after linear regression $\Delta I_{s} \Delta V_{l v}^{-1} V_{w}(\mu \mathrm{m})$ for the NORM and SYNC simulation (with a $95 \%$ confidence interval); MEAS measurements of Ref. 18.

\begin{tabular}{crcl}
\hline & NORM & \multicolumn{1}{c}{ SYNC } & \multicolumn{1}{c}{ MEAS } \\
\hline Epicardium, anterior & $1.09 \pm 0.0062$ & $0.780 \pm 0.0056$ & $0.653 \pm 0.099$ \\
Epicardium, posterior & $1.17 \pm 0.0087$ & $0.782 \pm 0.0057$ & $0.743 \pm 0.045$ \\
Midwall, anterior & $0.656 \pm 0.0017$ & $0.842 \pm 0.0024$ & $0.797 \pm 0.13$ \\
Midwall, posterior & $0.723 \pm 0.0031$ & $0.848 \pm 0.0027$ & $0.868 \pm 0.090$ \\
\hline
\end{tabular}


TABLE 5. Myofiber stress (mean $\pm s d$.) during ejection $\left(\sigma_{f, \mathrm{ej}}\right)$ and myofiber strain (mean $\pm s d$.) during isovolumic contraction $\left(\epsilon_{f, \text { ic }}\right)$ and ejection $\left(\epsilon_{f, \mathrm{ej}}\right)$ for the test simulations BOUN, HETER, and LSO. All simulations were performed with a regular depolarization pattern (NORM). The differences with the NORM simulation were expressed in the root-mean-square (RMS\%), relative to the volume-weighted means of the NORM simulation.

\begin{tabular}{|c|c|c|c|c|c|c|}
\hline & $\sigma_{f, \mathrm{ej}}$ & RMS\% & $\epsilon_{f, \text { ic }}$ & RMS\% & $\epsilon_{f, \mathrm{ej}}$ & $\mathrm{RMS} \%$ \\
\hline & $\mathrm{kPa}$ & $\%$ & $\cdots$ & $\%$ & $\cdots$ & $\%$ \\
\hline BOUN & $22.2 \pm 2.55$ & 4.4 & $-0.016 \pm 0.047$ & 28.4 & $-0.149 \pm 0.042$ & 8.1 \\
\hline HETER & $22.9 \pm 2.44$ & 5.8 & $-0.023 \pm 0.048$ & 8.5 & $-0.138 \pm 0.044$ & 1.31 \\
\hline LSO & $23.0 \pm 2.44$ & 5.1 & $-0.023 \pm 0.044$ & 21.7 & $-0.142 \pm 0.053$ & 8.5 \\
\hline
\end{tabular}

mural variation of resting sarcomere length. ${ }^{39}$ Such a variation affected myofiber strain and stress in systole in the LS0 simulation (Table 5), but did not affect the pattern of early shortening and prestretch, as observed in the NORM simulation.

Muscular tissue is about as incompressible as water, as shown by the high wave velocity for ultrasound [1550-1650 $\mathrm{m} \mathrm{s}^{-1}$ (Ref. 54)]. During a cardiac cycle, total tissue volume may change by no more than $3 \%$ (Refs. 51 and 57) due to shifts of coronary blood volume. We set compressibility parameter $a_{5}$ in Eq. (10) to $55 \mathrm{kPa}$, thus limiting tissue volume changes during the cardiac cycle to about $3 \%$.

The real cardiac geometry with a left and right ventricle is much more complex than the truncated ellipsoid we used. The load the RV exerts on the LV wall through $\mathrm{RV}$ pressure and force transmission in the LV-RV attachment were neglected. As RV pressure develops earlier than LV pressure, timing of stretch in the LV wall might be affected. However, the difference in timing of pressure [0-15 ms (Ref. 50)] is small with respect to the range of depolarization times during sinus rhythm. Also, due to the confocal description of the LV geometry, the apex is too thick. To minimize the influence of the right ventricle, apical region, and boundary conditions, we focused on deformation in the equatorial region of the LV free wall. It is unlikely that the used LV geometric imperfections have a significant impact on timing of contraction in this part of the left ventricle.

In summary, inaccuracies introduced by the assumptions made in the model may influence the pattern of myocardial contraction. None of these imperfections can, however, explain the differences in time course of systolic myofiber strain as found in comparing the NORM and SYNC simulation.

\section{Physiology}

In the NORM simulation propagation of depolarization was physiological (Fig. 5) in the following aspects. The LV depolarizes within 40-55 ms. ${ }^{13,14,36}$ Depolarization starts at the lower third of the LV endocardium, propagating to apex and base. ${ }^{28}$ The LV free wall and septum depolarized practically simultaneously. ${ }^{41} \mathrm{Com}-$ plete depolarization of the left, and right septal endocardium occurs within 21 and $40 \mathrm{~ms}$, respectively. ${ }^{14}$ The LV free wall is activated transmurally within $15-18 \mathrm{~ms}^{42}$

Despite the similarity in depolarization, strain patterns are significantly different between the NORM simulation and experiments. In experiments with sinus rhythm or atrial pacing, where depolarization is similar to that of the NORM simulation, systolic strains (Fig. 8, Tables 3 and 4) and stroke work (Fig. 9) have been shown to be distributed evenly throughout the ventricular wall. ${ }^{12,18,35,56}$ Experimental results are not different from the results of the SYNC simulation on sarcomere shortening (Table 4) during ejection. Myofiber strains during isovolumic contraction and ejection in the SYNC simulation are closer to measured strains (Table 3), than myofiber strains in the NORM simulation.

In the NORM simulation, however, the considerable differences in systolic strain pattern (Fig. 8) closely resembles the pattern as found in experiments during ventricular pacing, ${ }^{56}$ a situation of asynchronous depolarization. Under these circumstances, in early systole myofibers shorten in the early activated regions (Fig. 8, endocardium) and stretch in the late activated regions (Fig. 8, epicardium). Furthermore, both myofiber strain and stroke work are low in the early-activated regions, and high in the late activated regions. Exactly, these characteristics are also found in the mechanics of the NORM simulation.

Thus, our model predicts an unphysiological nonuniform contraction pattern during a physiological pattern of depolarization, and a physiological contraction pattern during an unphysiological synchronous depolarization. This finding suggests that myocardial tissue is able to synchronize contraction despite asynchrony of depolarization. It is not known yet what mechanism may be responsible for this behavior. Probably, there is a local controlling mechanism that makes contraction more synchronous than depolarization by proper variation of local electromechanical delay time. Actually, the SYNC simulation can be interpreted as a simulation with a normal depolarization pattern and a heterogeneous distribution 
TABLE 6. Used active material properties.

\begin{tabular}{lccccccccc}
\hline$a_{6}$ & $a_{7}$ & $T_{0}$ & $E_{a}$ & $v_{0}$ & $l_{s 0}$ & $t_{r}$ & $t_{d}$ & $b$ & $l_{d}$ \\
\hline$\mu \mathrm{m}^{-1}$ & $\mu \mathrm{m}$ & $\mathrm{kPa}$ & $\mu \mathrm{m}^{-1}$ & $\mu \mathrm{m} \mathrm{s}^{-1}$ & $\mu \mathrm{m}$ & $\mathrm{s}$ & $\mathrm{s}$ & $\mathrm{s} \mu \mathrm{m}^{-1}$ & $\mu \mathrm{m}$ \\
2.0 & 1.5 & 180 & 20 & 7.5 & 1.9 & 0.075 & 0.075 & 0.15 & -0.4 \\
\hline
\end{tabular}

of electromechanical delay times, which completely compensates for asynchrony of local depolarization.

Until now there is no direct experimental evidence for regional differences in electromechanical delay. However, the finding that expression of the $I_{\text {to }}$ channel is higher in the subepicardial layers than in the subendocardial layers ${ }^{40}$ may reflect the physiology of such mechanism. The $I_{\text {to }}$ channel has a prominent role in modulating the systolic calcium transient by enhancing the rise of the intracellular calcium concentration. As a result, the time elapsed between depolarization and contraction may be shorter in the subepicardial layers than in the subendocardial ones. Instead of phenomenologically adding electromechanical delay times, incorporating a ion-based model of heterogeneously distributed action potential ${ }^{17,33}$ into our model may yield better results, also. However, computation time would increase dramatically, losing the benefit of shorter computation time by using the eikonaldiffusion equation.

\section{CONCLUSIONS}

A three-dimensional finite element model of LV depolarization wave propagation and mechanics has been developed.

The simulated depolarization wave appeared physiologic. Then, the systolic myofiber strain distribution was unphysiologically inhomogeneous.

When simulating LV mechanics with unphysiological synchronous depolarization myofiber strain was more homogeneous and more physiologic.

Apparently, the delay between depolarization and onset of crossbridge formation is distributed such, that contraction is more synchronous than depolarization.

Furthermore, it was found that variations in timing of depolarization caused larger relative changes in the distribution of myofiber strain than in that of myofiber stress.

\section{ACKNOWLEDGMENT}

The study has been financially supported by Medtronic Bakken Research Center Maastricht.

\section{APPENDIX: MODEL OF ACTIVE STRESS DEVELOPMENT}

Active stress was dependent on sarcomere length $l_{s}$, length $l_{c}$ of the contractile element, and time $t_{a}$, elapsed since the moment of electrical depolarization:

$$
\sigma_{a}=f_{1}\left(t_{a}, l_{s}, l_{c}\right)=\frac{l_{s}}{l_{s 0}} f_{\text {iso }}\left(l_{c}\right) f_{\text {twitch }}\left(t_{a}, l_{s}\right)\left(l_{s}-l_{c}\right) E_{a},
$$

where $l_{s 0}$ represents the sarcomere length in the reference state, and $E_{a}$ is the stiffness of the serial elastic element.

The dependency of isometrically developed active stress on $l_{c}$ was represented by

$$
f_{\text {iso }}\left(l_{c}\right)=\left\{\begin{array}{cc}
T_{0} \tanh ^{2}\left[a_{6}\left(l_{c}-a_{7}\right)\right] & l_{c}<a_{7} \\
0 & l_{c}>a_{7},
\end{array}\right.
$$

which is similar to measurements of Ref. 20 on rat cardiac trabecula at an intracellular calcium concentration of approximately $7 \mu \mathrm{M}$.

The dependency of myofiber stress on $t_{a}$ and $l_{s}$ was represented by

$f_{\text {twitch }}\left(t_{a}, l_{s}\right)=\left\{\begin{array}{cc}0 & t_{a}<0 \\ \tanh ^{2}\left(\frac{t_{a}}{t_{r}}\right) \tanh ^{2}\left(\frac{t_{\text {max }}-t_{a}}{t_{d}}\right) & 0<t_{a}<t_{\text {max }} \\ 0 & t_{a}>0,\end{array}\right.$

with

$$
t_{\max }=b\left(l_{s}-l_{d}\right)
$$

where $t_{r}$ is the activation rise time constant, $t_{d}$ the activation decay time constant, and $t_{\max }$ the activation duration. Parameter $b$ relates activation duration to the length of a sarcomere $l_{s} . l_{d}$ is the sarcomere length at which this duration is 0 .

The time course of the contractile element length $l_{c}$ was simulated by a first order differential equation [function $f_{2}$ in Eq. (13)]: 


$$
\frac{\partial l_{c}}{\partial t}=\left(E_{a}\left(l_{s}-l_{c}\right)-1\right) v_{0}
$$

where $v_{0}$ represents the unloaded shortening velocity.

The values of the parameters are listed in Table 6.

Equation (A5) was solved using an Adams-BashfortMoulton multistep integration scheme. ${ }^{21}$

\section{REFERENCES}

${ }^{1}$ Aelen, F. W. L., T. Arts, D. G. M. Sanders, G. R. P. Thelissen, A. M. M. Muijtjens, F. W. Prinzen, and R. S. Reneman. Relation between torsion and cross-sectional area change in the human left ventricle. J. Biomech. 30:207-212, 1997.

${ }^{2}$ Aelen, F. W. L., T. Arts, D. G. M. Sanders, G. R. P. Thelissen, F. W. Prinzen, and R. S. Reneman. Kinematic analysis of left ventricular deformation in myocardial infarction using magnetic resonance cardiac tagging. Int. J. Card. Imaging 15:241-251, 1999.

${ }^{3}$ Allgower, E. L., and K. Georg. Numerical Continuation Methods: An Introduction. Berlin: Springer, 1990.

${ }^{4}$ Arts, T., P. C. Veenstra, and R. S. Reneman. A model of the mechanics of the left ventricle. Ann. Biomed. Eng. 7:299318, 1979.

${ }^{5}$ Arts, T., P. C. Veenstra, and R. S. Reneman. Epicardial deformation and left ventricular wall mechanics during ejection in the dog. Am. J. Physiol. 243:H379-H390, 1982.

${ }^{6}$ Bovendeerd, P. H. M., T. Arts, D. H. van Campen, and R. S. Reneman. Dependence of local left ventricular wall mechanics on myocardial fiber orientation: A model study. J. Biomech. 25:1129-1140, 1992.

${ }^{7}$ Bovendeerd, P. H. M., J. M. Huyghe, T. Arts, D. H. van Campen, and R. S. Reneman. Influence of endocardialepicardial crossover of muscle fibers on left ventricular wall mechanics. J. Biomech. 27:941-951, 1994.

${ }^{8}$ Brooks, A. N., and T. J. R. Hughes. Stream-line upwind/ Petrov-Galerkin formulation for convection dominated flows with particular emphasis on the incompressible NavierStokes equations. Comput. Methods Appl. Mech. Eng. 32:199-259, 1982.

${ }^{9}$ Colli-Franzone, P., and L. Guerri. Spreading of excitation in 3D models of the anisotropic cardiac tissue. I. Validation of the eikonal model. Math. Biosci. 113:145-209, 1993.

${ }^{10}$ Colli-Franzone, P., L. Guerri, M. Pennacchio, and B. Taccardi. Spreading of excitation in 3D models of the anisotropic cardiac tissue. II. Effects of fiber architecture and ventricular geometry. Math. Biosci. 113:145-209, 1998.

${ }^{11}$ Colli-Franzone, P., L. Guerri, and S. Tentoni. Mathematical modeling of the excitation process in myocardial tissue: Influence of fiber rotation on wave-front propagation and potential field. Math. Biosci. 101:155-235, 1990.

${ }^{12}$ Delhaas, T., T. Arts, P. H. M. Bovendeerd, F. W. Prinzen, and R. S. Reneman. Subepicardial fiber strain and stress as related to left ventricular pressure and volume. Am. J. Physiol. 264:H1548-H1559, 1993.

${ }^{13}$ Durrer, D., R. T. van Dam, G. E. Freud, M. J. Janse, F. L. Meijler, and R. C. Arzbaecher. Total excitation of the isolated human heart. Circulation 41:899-912, 1970.

${ }^{14}$ Durrer, D., J. P. Roos, and J. Büller. The spread of excitation in the canine and human heart. In: International Symposium on Electrophysiology of the Heart, edited by G. Marchetti and B. Taccardi. Oxford, U.K.: Pergamon, 1964.
${ }^{15}$ Gallagher, K. P., G. Osakada, O. M. Hess, A. Koziol, W. S. Kemper, and J. Ross, Jr.. Subepicardial segmental function during coronary stenosis and the role of myocardial fiber orientation. Circ. Res. 50:352-359, 1982.

${ }^{16}$ Geerts, L., P. Bovendeerd, K. Nicolay, and T. Arts. Characterization of the normal cardiac myofiber field in goat measured with MR-diffusion tensor imaging. Am. J. Physiol. 283:H139-H145, 2002.

${ }^{17}$ Greenstein, J. L., R. Wu, S. Po, G. F. Tomaselli, and R. L. Winslow. Role of the calcium-independent transient outward current $I_{\text {tol }}$ in shaping action potential morphology and duration. Circ. Res. 87:1026-1033, 2000.

${ }^{18}$ Guccione, J. M., W. G. O'Dell, A. D. McCulloch, and W. C. Hunter. Anterior and posterior left ventricular sarcomere lengths behave similarly during ejection. Am. J. Physiol. 272:H469-H477, 1997.

${ }^{19}$ Hunter, P. J., A. D. McCulloch, and H. E. D. J. ter Keurs. Modeling the mechanical properties of cardiac muscle. Prog. Biophys. Mol. Biol. 69:289-331, 1998.

${ }^{20}$ ter Keurs, H. E. D. J., J. J. J. Bucx, P. P. de Tombe, P. Backx, and T. Iwazumi. The effects of sarcomere length and $\mathrm{Ca}++$ on force and velocity of shortening in cardiac muscle. In: Molecular Mechanisms of Muscle Contraction, edited by H. Suga and G. H. Pollack. New York: Plenum, 1988, pp. 581-593.

${ }^{21}$ Kreyszig, E. Advanced Engineering Mathematics, 8th ed. New York: Wiley, 1999.

${ }^{22}$ LeGrice, I. J., B. H. Smaill, L. Z. Chai, S. G. Edgar, J. B. Gavin, and P. J. Hunter. Laminar structure of the heart: Ventricular myocyte arrangement and connective tissue architecture in the dog. Am. J. Physiol. 269:H571-H582, 1995.

${ }^{23}$ Lin, D. H. S., and F. C. P. Yin. A multiaxial constitutive law for mammalian left ventricular myocardium in steady-state barium contracture or tetanus. J. Biomech. Eng. 120:504517, 1998.

${ }^{24}$ Malvern, L. E. Introduction to the Mechanics of a Continuous Medium. Englewood Cliffs, NJ: Prentice Hall, 1969.

${ }^{25}$ Marcus, J. T., M. J. W. Götte, A. C. van Rossum, J. P. A. Kuijer, R. M. Heethaar, L. Axel, and A. Visser. Myocardial function in infarcted and remote regions early after infarction in man: Assessment by magnetic resonance tagging and strain analysis. Magn. Reson. Med. 38:803-810, 1997.

${ }^{26}$ Massing, G. K., and T. N. James. Anatomical configuration of the HIS bundle and bundle branches in the human heart. Circulation 53:609-621, 1976.

${ }^{27}$ Muzikant, A. L., and C. S. Henriquez. Validation of threedimensional conduction models using experimental mapping: Are we getting closer? Prog. Biophys. Mol. Biol. 69:205223, 1998.

${ }^{28}$ Myerburg, R. J., K. Nilsson, and H. Gelband. Physiology of canine intraventricular conduction and endocardial excitation. Circ. Res. 30:217-243, 1972.

${ }^{29}$ Nash, M. P., and P. J. Hunter. Computational mechanics of the heart. From tissue structure to ventricular function. $J$. Elast. 61:113-141, 2000.

${ }^{30}$ Nikolić, S., E. L. Yellin, K. T. Tamura, H. Vetter, T. Tamura, J. S. Meisner, and R. W. M. Frater. Passive properties of canine left ventricle: Diastolic stiffness and restoring forces. Circ. Res. 62:1210-1222, 1988.

${ }^{31}$ Novak, V. P., F. C. P. Yin, and J. D. Humphrey. Regional mechanical properties of passive myocardium. J. Biomech. 27:403-412, 1994.

${ }^{32}$ Omens, J. H., and Y. C. Fung. Residual strain in rat left ventricle. Circ. Res. 66:37-45, 1990.

${ }^{33}$ Pandit, S. V., R. B. Clark, W. R. Giles, and S. S. Demir. A 
mathematical model of action potential heterogeneity in adult rat left ventricular myocytes. Biophys. J. 81:3029-3051, 2001.

${ }^{34}$ Prinzen, F. W., C. H. Augustijn, T. Arts, M. A. Allessie, and R. S. Reneman. Redistribution of myocardial fiber strain and blood flow by asynchronous activation. Am. J. Physiol. 259:H300-H308, 1990.

${ }^{35}$ Prinzen, F. W., W. C. Hunter, B. T. Wyman, and E. R. McVeigh. Mapping of regional myocardial strain and work during ventricular pacing: Experimental study using magnetic resonance imaging tagging. J. Am. Coll. Cardiol. 33:17351742, 1999.

${ }^{36}$ Prinzen, F. W., and M. Peschar. Relation between the pacing induced sequence of activation and left ventricular pump function in animals. PACE 25:484-498, 2002.

${ }^{37}$ Rijcken, J., P. H. M. Bovendeerd, A. J. G. Schoofs, D. H. van Campen, and T. Arts. Optimization of cardiac fiber orientation for homogeneous fiber strain at beginning of ejection. $J$. Biomech. 30:1041-1049, 1997.

${ }^{38}$ Rijcken, J., P. H. M. Bovendeerd, A. J. G. Schoofs, D. H. van Campen, and T. Arts. Optimization of cardiac fiber orientation for homogeneous fiber strain during ejection. Ann. Biomed. Eng. 27:289-297, 1999.

${ }^{39}$ Rodriguez, E. K., J. H. Omens, L. K. Waldman, and A. D. $\mathrm{McCulloch}$. Effect of residual stress on transmural sarcomere length distribution in rat left ventricle. Am. J. Physiol. 264:H1048-H1056, 1993.

${ }^{40}$ Sah, R., R. J. Ramirez, and P. H. Backx. Modulation of $\mathrm{Ca}^{2+}$ release in cardiac myocytes by changes in repolarization rate-role of phase-1 action potential repolarization in excitation-contraction coupling. Circ. Res. 90:165-173, 2002.

${ }^{41}$ Scher, A. M., A. C. Young, A. L. Malmgren, and R. V. Erickson. Activation of the interventricular septum. Circ. Res. 3:56-64, 1955

${ }^{42}$ Scher, A. M., A. C. Young, A. L. Malmgren, and R. R. Paton. Spread of electrical activity through the wall of the left ventricle. Circ. Res. 1:539-547, 1953.

${ }^{43}$ Streeter, D. D. Gross morphology and fiber geometry of the heart. In: Handbook of Physiology-The Cardiovascular System I, edited by R. M. Berne, Bethesada, MD: American Physiology Society, 1979, Chap. 4, pp. 61-112.

${ }^{44}$ Taber, L. A., M. Yang, and W. W. Podszus. Mechanics of ventricular torsion. J. Biomech. 29:745-752, 1996.

${ }^{45}$ Tomlinson, K. A. Finite element solution of an eikonal equa- tion for excitation wave-front propagation in ventricular myocardium. PhD thesis, The University of Auckland, 2000.

${ }^{46}$ van der Toorn, A., P. Barenbrug, G. Snoep, F. H. van der Veen, T. Delhaas, F. W. Prinzen, and T. Arts. Transmural gradients of cardiac myofiber shortening in aortic valve stenosis patients using MRI-tagging. Am. J. Physiol. (in press).

${ }^{47}$ Usyk, T. P., I. J. LeGrice, and A. D. McCulloch. Computational model of three-dimensional cardiac electromechanics. Comput. Visual Sci. 4:249-257, 2002.

${ }^{48}$ Usyk, T. P., R. Mazhari, and A. D. McCulloch. Effect of laminar orthotropic myofiber architecture on regional stress and strain in the canine left ventricle. J. Elast. 61:143-164, 2000.

${ }^{49}$ Vassal-Adams, P. R. Ultrastructure of the human atrioventricular conduction tissues. Eur. Heart J. 4:449-460, 1983.

${ }^{50}$ Verbeek, X. A. A. M., K. Vernooy, M. Peschar, T. van der Nagel, A. van Hunnik, and F. W. Prinzen. Quantification of interventricular asynchrony during LBBB and ventricular pacing. Am. J. Physiol. 283:H1370-H1378, 2002.

${ }^{51}$ Vergroesen, I., M. I. M. Noble, and J. A. E. Spaan. Intramyocardial blood volume change in first moments of cardiac arrest in anesthetized goats. Am. J. Physiol. 253:H307-H316, 1987.

${ }^{52}$ Villareal, F. J., W. Y. W. Lew, L. K. Waldman, and J. W. Covell. Transmural myocardial deformation in the ischemic canine left ventricle. Circ. Res. 68:368-381, 1991.

${ }^{53}$ Waldman, L. K., J. W. Covell. Effects of ventricular pacing on finite deformation in canine left ventricles. Am. J. Physiol. 252:H1023-H1030, 1987.

${ }^{54}$ Wells, P. N. T. Physical Principles of Ultrasonic Diagnosis. New York: Academic, 1969.

${ }^{55}$ Westerhof, N., G. Elzinga, and G. C. van den Bos. Influence of central and peripherical changes on the hydraulic input impedance of the systemic arterial tree. Med. Biol. Eng. 11:710-723, 1973.

${ }^{56}$ Wyman, B. T., W. C. Hunter, F. W. Prinzen, and E. R. McVeigh. Mapping propagation of mechanical activation in the paced heart with MRI tagging. Am. J. Physiol. 276:H881-H891, 1999.

${ }^{57}$ Yin, F. C. P., C. C. H. Chan, and R. M. Judd. Compressibility of perfused passive myocardium. Am. J. Physiol. 271:H1864-H1870, 1996. 